problem of the differentiation of the carly lorisid stock. As Simpson has shown, there seems to be no single cranial or dental eriterion by which the Lorisinae can be distinguished from the Galaginae when dealing with these fossil forms. It now seems that the Miocene lorisids were represented by two genera (Komba Simpson, 1967, with two species, and Progalago MacInnes, 1948, with three species), and that they still possessed the primitive Galago-like morphological habit, both cranially and postcranially (postcranial remains of the Miocene Lorisidae of East Africa are now known ${ }^{3}$ ). There is a little evidence to suggest that Progalago has more lorisine characters and Komba more galagine characters, but these aspects can, perhaps, be over cmphasized. It may be, as karyological' and immunochemical ${ }^{5}$ evidence suggests, that the two sub-families do not represent a single basic split of the early lorisid stock, but that species with the lorisine morphological habit were evolved several times from the more primaitive Galago-like, early lorisids. Some species of Galago may be more closely related to some lorises than they are to other Galago species. With our present state of knowledge it seems that the major division or divisions of the Lorisidae into the two sub-families probably took place in Africa during or just after the Miocene.

I thank Professor G. G. Simpson for reading this communication. He has asked mo to state that he agrees with my interpretation.

Department of Anatomy, Makerere University College, Kampala, Uganda.

Received May 27, 1969.

${ }^{1}$ Simpson, G. G., Bull. Mus. Comp. Zool., 136, 39 (1967).

'Dal Piaz, G., Mem. First Geol. Univ. Padova, 11, 1 (1937).

s Walker, A., Nature, this issue, 223, 591 (1969).

- Bender, M. A., and Chı, E. H. Y., in Evolutionary and Genetic Biology of Primates, 1 (edit, by Buettner-Janusch, J. (New York, 1963). ${ }^{5}$ Goodman, M., Amer. J. Phys. Anthrop., 26, 255 (1967).

\section{Possible Identity of Miocene Tali from Kenya}

Day and Wood have very elegantly shown that three hominoid tali from the early Miocene of Kenya are functionally similar to those from the living pronograde quadrupedal African apes, Pan and Gorilla, and unlike modern bipedal man'. Two of the tali (CMH 145 from Songhor and CMH 147 from Rusinga) were described first by MacInnes ${ }^{2}$ and later more fully by Le Gros Clark and Leakey ${ }^{3}$; Le Gros Clark subsequently described a second talus from Rusinga ${ }^{4}$. I have some tentative suggestions concorning their identification.

In the early 1950 s three medium sized pongid species to which these tali might belong were known from the East African Miocene: P'roconsul nyanzae, $P$. major and Sivapithecus africanus ${ }^{3}$. Simons and I subsequently transferred all three species to Dryopithecus ${ }^{5}$, the last to $D$. sivalensis. Alternatively Leakey has reclassified "S. africanus" as "Kenyapithecus africanus", a specios ho believes to be a hominid ancestral to the late Miocene horninid "K. wickeri" $i$. I have argued elsewhere", as have others", that "K. wickeri" is a Ramapithecus, and that "K. africanus" is a Dryopithecus probably not ancestral to Ramapithecus.

Le Gros Clark and Loakey stated initially ${ }^{3}$ that the tali belonged most probably in Dryopithecus (Proconsul) nyanzae, although they did point out that these bones might just possibly belong to the very rare "S. africanus". The possibility that they might represent $D$. (P.) major, also rare, was not considered. In 1952, Le Gros Clark stated definitely that the tali belonged in $D$. (P.) nyanzae $e^{4}$. Since 1952, many more spccimens of $D$. (P.) major have been discovered or recognized ${ }^{9,10}$, and the possibility that the three tali are not all $D$. $(P$.) nyanzae should now be considered.

The canonical analysis ${ }^{1}$ showed that the Miocene tali are close to Pan and Gorilla. One striking feature of the canonical plots, however, is that the three bones do not form a homogeneous cluster. The two from Rusinga fall close together, lying some 2 standard deviations from the mean of Pan on plots of both variates $\mathrm{I}$ and II, and $I I$ and IIII. They lie outside the 2 standard deviation arcas of Gorilla. In contrast, the Songhor talus lies well away from the Rusinga specimens, 2 standard deviation units or more away on both plots. The Songhor and Rusinga samples are farther apart than are the means of Pan and Gorilla (and also more disparate in these terms than the hominid tali from Olduvai and Kromdraai which are assigned to two separate species by almost all students ${ }^{11}$ ). In the plot of variates I and II, the Songhor talus lies within the 2 standard deviation range of Gorilla and on the edge of that range for Pan; in the plot of II and III the Songhor specimen is closer to the Gorilla mean while the Rusinga sample is closer to that of Pan.

Although the samples are minimal, it secms quite likely therefore that these three tali are drawn from two species, one represented at Songhor and another at Rusinga. CMH 145 from Songhor and CMH 147 from Rusinga were illustrated comparatively by Le Gros Clark and Leakey ${ }^{3}$, and a careful examination of the plates reveals morphological contrasts between the two (including sorne features not utilized in the canonical analysis).

What of the identity of these two species? By far the most abundant medium sized primate recovered from Rusinga is $D$. (P.) nyanzae $e^{3,4,9,10}$, and the Rusinga tali can be assigned with some confidence to that species, as Le Gros Clark suggested ${ }^{4}$.

$D$. (P.) major, only poorly known from Rusinga, is well represented at Songhor. This species was on average larger than $D .(P$.$) nyanzae, although the two overlap in$ size. I have suggested that several so-called $D .(P$. nyanzae from Songhor and elsewhere are females of $D$. $(P$.) major, and that this species may well be the most common large primate in the Songhor deposits ${ }^{9,10}$. A phylogenetic relationship between D. (P.) major and Gorilla has also been proposed following a detailed analysis of dental, mandibular and facial morphology $y^{3,10}$. Walker and Rose, in describing a $D$. $(P$.$) major lumbar vertebra$ from Moroto in Uganda, state that there are no vertebral features which would rule $D$. (P.) major out of Gorilla ancestry ${ }^{12}$. Because the Songhor talus scems not to be $D(P$.) nyanzae it is probably $D$. (P.) major, and its close similarity to Gorilla rather than to Pan then provides additional supporting evidence in favour of an evolutionary relationship between $D$. $(P$. ) major and Gorilla. Whether or not such a rolationship is eventually proven, Day and Wood's analysis shows that largo pongids with several resemblances to the living African apes had differentiated in Africa during the early Miocene.

Anthropology Department,

David Pilbeam

Yale University,

New Haven, Connecticut.

Received Junc 2, 1909.

${ }^{1}$ Day, M. H., and Wood, B. A., Nature, 222, 591 (1969).

2 MacInnes, D. G., J. East Africa and Vganda Nat. Hist. Soc., 1\%, 141 (1943).

${ }^{3}$ Ie Gros Clark, W. E., and Leakey, T. S. B., The Miocene Hominoidea of East Africa, Fossil Mammals of Africa, No. 1 (Brit. Mus. (Nat. Hist.), 1951).

4 Le Gros Clark, W. E., Proc, Zool. Soc, 122, 173 (1952).

- Simons, Ka. L., and Pilbeam, D. R., Folia Primatol., 3, 81 (1965).

- Leakey, X. S. B., Nature, 213, 155 (1967).

? Pilbeam, D., Nature, 219, 1335 (1968).

8 Simons, E. L., Nature, 221, 448 (1909).

Y Pilbeam, D. R., thesis, Yale Univ. (1067).

10 Pilbeam, D. R., Peabody Museum Bull., 31 (1969),

"I Day, M. H., and Wood, B. A., Man, 3, 440 (1968).

19 Walker, A., and Rose, M. D., Nature, 217, 980 (1968). 